\title{
Mercado y fe. Discusión entre Economía Ortodoxa y Teología de la Liberación. Lecturas de Franz Hinkelammert
}

\author{
Hugo Amador Herrera Torres \\ Universidad Michoacana de San Nicolás de Hidalgo, Michoacán, México \\ Email: hugoht@fevaq.net \\ María Arcelia Gonzáles Butrón \\ Universidad Michoacana de San Nicolás de Hidalgo, Michoacán, México \\ Email: gbutro<n6@yahoo.com.mx
}

\author{
José Antonio Toledo García \\ Universidad de La Habana, La Habana, Cuba \\ Email: jat@ffh.uh.cu
}

\begin{abstract}
Resumen: En la producción teórica de Franz Hinkelammert se identifica el centro nodal de discusión entre la Economía Ortodoxa y la Teología de la Liberación: la idolatría. En la idolatría se producen ídolos como producto de la imaginación dominadora del individuo, ídolos que se convierten en la referencia para decidir la validez de todo lo demás. Los ídolos exigen veneración, al venerarse se transforman en dioses. El mercado ha llegado precisamente a ese punto en el neoliberalismo monetarista. La fe de hoy consiste en seguir la ley del mercado, que es la ley funcional de la sociedad. No obstante, esta ley, en sus principios, posee la peor forma de destruir al ser humano: convertirlo en individuo egoísta, poseedor y calculador. El mercado, siendo así, es entonces un dios destructivo. Hinkelammert sostiene que la libertad del ser humano viene de la relativización de esta ley (y de cualquier otra ley) en función de la vida. La fe consiste en reconocer que la ley no es válida si conduce hacia la destrucción. La fe es la avenencia con la vida humana y el desacuerdo con la destrucción humana.

Palabras clave: mercado, fe, Economía Ortodoxa, Teología de la Liberación, Hinkelammert.
\end{abstract}

\section{Market and faith. Discussion between Orthodox Economics and Liberation Theology. Readings on Franz Hinkelammert}

\footnotetext{
Abstract: In the theoretical production of Franz Hinkelammert is identified a central point the discussion between Orthodox Economics and Liberation Theology: idolatry. In idolatry, idols are a product of the dominating imagination
} 
of the individual, idols that are converted in the basis for deciding the validity of everything else. Idols require worship, and by being worshiped become gods. The market has become precisely that in monetarist neoliberalism. Todays faith is the obedience the laws of the market, which is the functional law of society. However, this law, in its principles, has the worst way to destroy the human being: transforming him into a selfish, possessive and calculating individual. The market is thus a destructive god. Hinkelammert argues that human freedom comes from the relativization of this law (and of any other law) in function of life. Faith is to recognize that law is not valid if it leads to destruction. Faith is the compromise with human life and the disagreement with human destruction. Hinkelammert.

Key words: market, faith, Orthodox Economics, Liberation Theology,

\section{Mercado e fé. Discussão entre economia ortodoxa e Teologia da Libertação. Leituras Franz Hinkelammert}

Resumo: Em a produção teórica de Franz Hinkelammert é identificado como centro nodal da discussão entre a economia ortodoxa e Teologia da Libertação, a idolatria. Em a idolatria são producidos ídolos como produto dominador da imaginação do indivíduo, ídolos se tornar o ponto de referência para decidir a validade de tudo que ocorre. Exigir adoram ídolos, para se tornar deuses venerados. O mercado chegou precisamente a esse ponto no neoliberalismo monetarista. A fé hoje é seguir a lei do mercado, que é a lei funcional da sociedade. No entanto, esta lei, em princípio, tem a pior forma de destruição para os seres humanos: transformá-lo em indivíduo titular egoísta e calculador. O mercado, sendo assim, é então um deus destrutivo. Hinkelammert argumenta que a liberdade humana é a relativização da lei (e qualquer outra lei ) como uma função da vida. Fé é reconhecer que a lei é válida se ela leva a destruição. A fé é o compromisso com a vida humana e discordar com a destruição humana.

Palavras-chave: mercado, fé, Economia Ortodoxa, Teologia da Libertação, Hinkelammert.

\section{Introducción}

La riqueza no es posesión de objetos ni de dinero, no es sinónimo de riqueza material. La riqueza, para la Teología de la Liberación, está en la plenitud de la vida, plenitud que se constituye a partir de que los seres humanos se reconocen -entre ellos mismos- como seres humanos: los unos miran su rostro en el rostro de los otros. Este reconocimiento configura la concepción de sujeto viviente. Dios está presente cuando existe este reconocimiento y Dios está ausente cuando se pierde este reconocimiento.

En la interpretación económica-teológica ortodoxa, la fe consiste en cumplir la ley funcional de la sociedad. Esta ley no es la constitución política ni el código civil ni ninguna ley promulgada por los poderes legislativos ni tampoco los diez mandamientos. La ley funcional de la sociedad es la ley del mercado. El mercado no solo es un espacio para intercambiar 
mercancías, es mucho más, es una ley que determina, condiciona y guía el comportamiento de los seres humanos, les impone, por lo menos, dos principios de conducta: egoísmo y maximización del interés propio. Sus principios forman relaciones donde los seres humanos se reconocen -entre ellos mismos- como individuos poseedores y calculadores, quedando negada la noción de sujeto viviente. En esta sociedad, manejada por el mercado, Dios

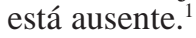

El presente artículo tiene como objetivo identificar el tema -o los temas- que orientan la discusión entre la Economía Ortodoxa y la Teología de la Liberación a la luz de las reflexiones económicas-teológicas de Franz Hinkelammert. ${ }^{2}$ En la Economía Ortodoxa subyace la teoría económica clásica, la teoría económica neoclásica, la síntesis neoclásica-keynesiana y todas las demás propuestas que toman como plataforma los planteamientos económicos de estas corrientes (por ejemplo, el neoliberalismo monetarista, la economía ambiental). El mercado juega un papel preponderante en el esquema de la Economía Ortodoxa, incluso, a esta última se le pudiera llamar Economía de Mercado. ${ }^{3}$

La producción teórica de Hinkelammert resulta explosiva: asocia economía con teología, relaciona lo terrenal con lo celeste, vincula explotación capitalista con religiosidad imperial. El pensamiento de este autor es pionero en este campo y ofrece importantes aportaciones para el desarrollo de una economía hacia la vida y de una teología emancipadora desde el excluido del mercado (Tamayo, 2001: 287). El golpe militar chileno de 1973 fue el acontecimiento clave que detonó su producción económicateológica. Hinkelammert (2001: 17-42) escribe que durante el golpe, los sacerdotes que tenían la voz en el canal de la Universidad Católica lanzaban emblemas religiosos tomados de una larga tradición cristiana represiva. Eran frases a favor del golpe. Se percató que había un pasado oscuro en el cristianismo, un pasado que tenía un impacto violento en los sacerdotes. Más tarde, en 1977, en su libro Ideologías del sometimiento, bautizó la teología de estos sacerdotes con el título de La Teología de la Masacre.

En Chile, antes del golpe militar, Hinkelammert ya había trabajado con algunos teólogos de la liberación: Hugo Assmann, Juan Luis Segundo, Pablo Richard. Esta corriente teológica, cuya acción giraba en la praxis de liberación del pobre (el excluido del mercado) y en el análisis teológico de la realidad social, tomaba como soporte la teoría de la dependencia; empero, todavía no había una crítica al núcleo de la Economía Ortodoxa. Los aportes de Hinkelammert ayudaron -y siguen ayudando- a fortalecer esta parte de la Teología de la Liberación. Sostuvo -y continúa sosteniendo- que el mercado manejado por la tradición económica ortodoxa es una versión secularizada de conceptos teológicos de estados de convivencia perfectos, ausentes de conflictos. La sociedad perfecta producida por el mercado viene de la noción religiosa de Reino de dios.

Los principios de la ley del mercado se presentan en la primera parte de este artículo. Se toma como base el pensamiento de Adam Smith, 
difundido desde el siglo XVIII. Este economista escocés es el máximo representante de la teoría económica clásica. En la segunda parte, se analiza el mito del sacrificio de Isaac por su padre Abraham, como hecho fundante de la liberación de la víctima (el excluido del mercado). En este mito se afirma al ser humano como ser humano (sujeto viviente). Se presenta también el mito del sacrificio de Ifigenia por su padre Agamenón (versión de Eurípides), donde se niega el reconocimiento del ser humano como ser humano. Se muestra un tercer mito en esta parte, la crucifixión de Jesús. Hinkelammert lo expone como la prueba de maldad que puede haber en la ley cuando en su cumplimento se exige la aniquilación del ser humano.

En la tercera parte, y última, se identifica al ser humano como ente social de análisis y discernimiento de la economía y teología. Se precisa que los seres humanos son libres en la medida que son capaces de relativizar la ley (como la ley del mercado) en función de su propia vida. La fe -asíconsiste en reconocer que la ley no es válida si niega la vida, que la fe no es posible sin la afirmación del ser humano como ser humano (sujeto viviente). En una sociedad, bajo la relación fe/vida, Dios está presente. Al final del artículo aparecen las conclusiones obtenidas (que en vez de cerrar el tema, lo abren más) y las fuentes bibliográficas utilizadas., ${ }^{4,5}$

\section{Egoísmo y maximización del interés propio: principios de la ley del mercado}

La ley del mercado se presenta en la sociedad actual como irrefutable. No se aceptan cuestionamientos ni discusiones sobre su vigencia, pues el mercado ha ocupado una posición similar a la que tuvo la escalera de Jacob. Jacob soñó con una gran escalera apoyada en la Tierra, cuya punta tocaba con el cielo. Los ángeles de dios subían y bajaban por esa escalera (Génesis). El mercado se ha instaurado sobre la Tierra, según los defensores de la Economía Ortodoxa, para orientar a la humanidad sobre cómo conquistar la sociedad perfecta (el cielo).

La ley del mercado comienza su consolidación en el siglo XVIII con la obra Investigación sobre la naturaleza y las causas de la riqueza de las naciones de Adam Smith. Esta ley postula que cada individuo debe comportarse con base en su interés propio, y el mercado se encargará de asegurar que este interés se satisfaga al momento que este mismo pueda satisfacer el interés de otro. Cada individuo servirá a otro individuo y cada uno recibirá según lo que haya logrado en el mercado. El mismo Smith escribe: dame tú, lo que me hace falta, que yo te daré a ti, lo que te hace falta. El mercado convierte, siguiendo este planteamiento, el interés propio en interés del otro (Hinkelammert, 1995: 338).

Pedir benevolencia es de animales: el perro si quiere conseguir un hueso de su amo, lo pide. Lo que corresponde al ser humano, dice Smith, es actuar con base en su interés propio, utilizando al mercado para lograrlo. El 
mercado -continúa explicando Smith- permite servir al otro, y este servicio dado es como servirse a sí mismo. Un individuo nunca se propone originalmente promover el interés general, siempre busca primero su interés. Esto no es malo, al contrario, es bueno, es el fundamento de la armonía social. El mercado, con una mano invisible, se ocupa de promover el interés general con la sola búsqueda del interés propio. Lo que había preocupado tanto a la humanidad había quedado resuelto con el mercado, según Smith. La diferencia entre interés propio e interés general se había eliminado, ya formaban una sola entidad: uno dependía del otro (Ibíd: 339). ${ }^{6}$

Percibiendo al interés propio como amor propio y al interés general como amor al prójimo, el mercado se consolida como el gran promotor del amor. Al descubrir que el mercado es amor, la doctrina económica ortodoxa se sintió con el derecho de promoverlo en toda la Tierra. Desde el siglo XVIII no ha parado. La Tierra, en todas sus dimensiones, se ha llenado de este amor, que ahora -incluso- las miradas de algunos economistas ortodoxos se dirigen hacia Marte, Júpiter, Saturno o Neptuno, pues todo el universo merece recibir el amor del mercado. ${ }^{7}$

Al percibirse la ley del mercado como la gran fuente del amor, se entra directamente al campo de la teología, que en su versión más ortodoxa, ha mostrado un discurso orientado al cumplimiento de esta ley. ${ }^{8} \mathrm{El}$ teólogo católico Michel Novak subraya que el mercado posibilita el desarrollo de las capacidades humanas, fomenta el espíritu de superación personal y permite aplicar la inteligencia práctica a la actividad económica (tal como lo planteaba Smith). La Teología Ortodoxa ha reconocido que el mercado definitivamente tiene raíces evangélicas (Tamayo, 2001: 289), pues es el constructor de una sociedad perfecta (Reino de dios), que solo puede alcanzarse con la expansión de este. Parafraseando al mismo Novak: si el mercado abrazara a la Tierra, más rápido sería el paso hacia el cielo.

La realidad, sin embargo, muestra con evidencias contundentes que detrás de tanto amor hay un gran des-amor. Se trata de una inversión espectral, del fetichismo de Marx. Con la expansión del mercado sobre la Tierra se constituyó el mercado total, se transformó en la única referencia. Sus autores han presentado a este suceso como el fin de la historia: mercado total/juicio final. Con la totalización del mercado se invisibilizaron las relaciones sociales entre los seres humanos. El mercado, aun sin totalizarse, sigue ocultando estas relaciones sociales. Se trata de grados de intensidad. El mercado tiene implícito en sus principios -en tanto ley- la peor forma de destruir la humanidad: convertir al ser humano en individuo egoísta, poseedor y calculador. Es un individuo, que al buscar su interés propio, se ve a sí mismo como calculador, que interactúa con una sociedad compuesta por meras mercancías. Es un individuo que reduce las relaciones sociales a relaciones mercantiles. Reconoce al otro solo cuando puede participar en el mercado, solo cuando es propietario de mercancías. Marx (1966: I, 48) argumentaba que las mercancías no pueden acudir por ellas mismas al mercado, son los poseedores quienes las llevan. Para que las mercancías se relacionen entre sí, es necesario que sus poseedores se relacionen entre 
ellos, morando sus voluntades en las mercancías, de tal manera que cada poseedor solo puede apoderarse de las mercancías del otro por voluntad de este y desprendiéndose de la suya propia. Ambos necesitan reconocerse como individuos poseedores.

El reconocimiento entre seres humanos, bajo los principios del mercado, no puede darse porque queda negada la condición humana, el reconocimiento que crean estos principios es entre individuos poseedores de mercancías. El ser humano no desaparece en este tipo de reconocimiento, pero su condición se invisibiliza, se oscurece. Al morar la voluntad en las mercancías, la voluntad de los individuos se determina por la relación entre las mercancías, se fija por el poder que resulta de poseerlas. El individuo se reconoce como poseedor y el mercado solo admite este tipo de reconocimiento. Aparece el individuo descrito por Hobbes: el hombre movido por el principio inercial de la posesión.

No solo basta reconocer al otro como poseedor, es necesario mirarlo también como enemigo -en tanto- tenga las mismas mercancías, deben luchar entre ellos para entrar a la relación mercantil con el individuo que logre vencer en otra lucha similar. El objetivo de llegar a esta relación es apoderarse del producto de las mercancías: el capital dinero. Estas luchas siguen siendo presentadas como expresión genuina de amor. A la lucha se le llama competencia y a los enemigos se les nombra competidores. Esta lucha y estos enemigos fueron explicados en la economía clásica, pero su argumentación no dejó ver el nivel de radicalización que pudieran alcanzar. En la obra marxiana sí se detectó. Detrás del reconocimiento entre poseedores-enemigos hay un doble pensamiento de aniquilamiento: 1) aniquilamiento de aquellos que no caben en la lucha, eliminación de los que no poseen mercancías; y 2) aniquilamiento de los poseedores-enemigos (competidores). Se trata de la eliminación de los perdedores, de aquellos que no lograron imponerse en la lucha (competencia). Los excluidos y los perdedores son las víctimas, que a final de cuentas, se unen en una sola clase: los aniquilados del mercado. ${ }^{9}$

La aniquilación ahora es para todos, también para los que ganan en la lucha. Este es el punto radical del mercado (neoliberalismo monetarista). Detectado también por Marx siglos atrás. Las víctimas ya son tres: los excluidos, los perdedores y los ganadores. No aparece una polarización entre ganadores (quienes mantienen la capacidad de intercambiar mercancías en la lucha) y excluidos/perdedores. El aniquilamiento es general. El mercado aniquila a los tres como consecuencia de su propia acción. Abstrae al ser humano de sus cálculos. Abstrae la redondez de la Tierra en sus operaciones. Su imagen de la Tierra es la de una planicie infinita en la cual se destruye una parte para pasar a otra y a otra, sin tener problemas de escasez. Habla de la producción de mercancías sin hablar de la reproducción del ente humano que produce las mercancías (abstracción del ser humano), tampoco habla de la naturaleza, de la cual se extraen las materias primas para la producción de mercancías (abstracción del entorno natural). Estas abstracciones, hace ciega su acción en relación con los problemas de la 
vida humana y natural. Hinkelammert (1995: 274) diseñó una escena para ejemplificar esta situación: hay dos productores que son competidores en el mercado, están sentados sobre la rama de un árbol, que representa a la naturaleza. Ambos están cortándola con serruchos bien afilados. El ganador será aquel que logre cortarla con menos serruchos y con mayor rapidez. La rama caerá pero con ella también caerán los dos competidores. No obstante, alguno de los dos habrá ganado la competencia. Sobre esta rama, que es la naturaleza, están también sentados los demás: los excluidos. El mercado, como muestra la escena, resulta un salto al vacío.

La canalización de la acción humana por el cálculo del interés propio a través del mercado está en cuestión. La ley del mercado se encuentra en tela de juicio. Sus consecuencias han puesto en peligro las dos condiciones principales que posibilitan la vida en la Tierra: al ser humano y a la naturaleza. Por eso es potencialmente destructiva. El cálculo del interés propio mediante el mercado requiere abstraer estas dos condiciones. En la teoría económica neoclásica, estas condiciones aparecen como externalidades. No se puede calcular nada con exactitud sin abstraerlas. Todo cálculo implica tiempo porque todo existe en el tiempo y el tiempo no es tiempo lineal (el tiempo que marca reloj) sin estas abstracciones. El cálculo presupone el tiempo lineal. Solamente abstrayendo la vida humana y natural se puede pensar en tiempo lineal, continuo y sin fin (Hinkelammert, 2012: 5).

Considerando la vida humana y la naturaleza hace que el cálculo no tenga validez. Calcular la producción de 1000 productos en 3 meses requiere de la expulsión de la vida humana y natural, pues contemplar que durante los 3 meses de producción, el productor puede lastimarse las piernas, perder los dedos de la mano, tener alteraciones en el corazón hasta el grado de infartarse, hace que el cálculo se vuelva falso, porque no es posible saber si la producción se logrará en ese tiempo. Sin estas abstracciones es difícil plantear la meta. Desde el comienzo de la historia de la humanidad los cálculos han tenido que recurrir a estas abstracciones. En la teoría económica neoclásica, las abstracciones son presentadas como fenómenos secundarios (externalidades), en el neoliberalismo monetarista de manera más nítida aparecen, prácticamente son borradas del cálculo. Sin embargo, desde el punto de vista del sujeto viviente, en estas abstracciones se halla la esencia humana, el asunto sustancial. Marx (1966: I, 423-424), en El Capital, ya escribía que la producción capitalista solo sabe desarrollar la técnica y la combinación del proceso social de producción socavando al mismo tiempo las fuentes originales de toda riqueza: la tierra en tanto naturaleza y el trabajador en cuanto ser humano. ${ }^{10}$

El aniquilamiento de los participantes en la lucha mercantil no implica solamente la desaparición de ellos sino el aniquilamiento de toda la humanidad. Este aniquilamiento se convierte en suicidio. Por eso, el mercado es potencialmente auto-destructivo. Habla de conquistar una sociedad perfecta, cuya búsqueda implica la aniquilación de todos. Se trata entonces de acciones y fines sin sentido (Hinkelammert, 1995: 275-285). El socialismo prometió algo similar: cumpliendo los mandatos del Estado (pla- 
nificación centralizada) se abrirán las puertas del comunismo (sociedad perfecta). Los resultados fueron parecidos, de mercado total/juicio final se pasó a Estado total/juicio final. La vida humana sometida a cualquier ley por tanto- significa su propia negación.

\section{Liberación y dominación: mitos fundantes}

Hinkelammert maneja algunos mitos anclados a la tradición cristiana y griega que le permiten interpretar la historia del ser humano en cuanto quiere liberarse o en cuanto quiere dominar. La sociedad de hoy -y también las sociedades anteriores- se asientan en mitos: los adoptan, los transforman, incluso, los producen. El análisis de los mitos muestra que el pensamiento mítico no es irracional e irreal, al contrario, es racional y real, aunque no incluya conceptos. El mito revela mediante imágenes, relatos y cuentos las bases sobre las cuales se forman los conceptos y las mismas sociedades (Hinkelammert, 2003: 75). En efecto, la sociedad actual no carece de mitos, los usa como argumentos para justificar las acciones en que incurre.

Hay mitos donde está presente la afirmación del ser humano como sujeto viviente, basados en el no-aniquilar, que expresan una visión de la sociedad desde el aniquilado: el sacrificio de Isaac por su padre Abraham (versión de Hinkelammert). También hay mitos escritos desde el aniquilador, donde está presente la negación del ser humano como sujeto viviente. Son mitos basados en el aniquilamiento, que muestran una visión de la sociedad desde el aniquilador: el sacrificio de Ifigenia por su padre Agamenón (versión de Eurípides interpretada por Hinkelammert). Hay un mito bíblico muy especial, en cuyas escenas está presente el aniquilar y el no-aniquilar. En este se aniquila, pero es un aniquilamiento que transparenta lo absurdo de aniquilar en nombre de la ley, muestra el sin sentido del aniquilar. Este aniquilamiento revela la maldad de la ley en cuanto elimina al ser humano en su cumplimiento y refleja -a la vez- el sentido del noaniquilar, que constituye la afirmación del sujeto viviente. Se trata del mito de la crucifixión de Jesús (interpretación de Hinkelammert).

\section{El sacrificio de Isaac por su padre Abraham}

Este mito, relatado en el Génesis muestra al sacrificio (aniquilamiento) como necesario para afirmar la ley (mandatos que condicionan la conducta humana). En la lectura cristiana ortodoxa, dios quiso probar la fe de Abraham mediante el sacrificio de su propio hijo, Isaac. Pidió que se lo ofreciera en holocausto. Abraham fue obediente y llevó a su hijo a la montaña para sacrificarlo. Cuando estaba a punto de hacerlo, dios le habló desde el cielo, exigiéndole que no lo hiciera. Dios salvó la vida de Isaac. La buena disposición del padre para sacrificar a su hijo bastó a dios para probar su fe, premiándolo con bendiciones.

En la ortodoxia cristiana es leído así, pero el mito es extraño. Hinkelammert (1995: 345) afirma que esta lectura no corresponde al texto. 
Bien leído, la fe de Abraham es lo inverso de lo relatado. La fe se probó al no sacrificarlo. Cuando el padre se acercó a su víctima, esta se resistió. Abraham se da cuenta de que esta exigencia de aniquilamiento no puede venir de Dios, y dice: no. En vez de sacrificarlo, lo salvó para Dios. Se puso por encima de la ley y la ajustó a la vida del ser humano. Dios reconoció esto como fe.

Hay varias referencias en la misma Biblia que pueden aclarar este mito: Jeremías niega toda posibilidad de que Dios haya pedido tal sacrificio. Con Ezequiel se deduce que Dios no exige actos de horror al ser humano como pruebas de fe. En un texto análogo sobre David queda claro que el sacrificio que pidió dios a Abraham era en verdad un sacrificio que pidió Satanás. No puede ser voluntad de Dios que se aniquilen a seres humanos (Ibíd: 346). Cuando Jesús discute con los fariseos, ellos le dicen: somos los hijos de Abraham. Jesús les responde: no sois los hijos de Abraham porque -ustedes- queréis matarme (aniquilarme) y Abraham no mató (aniquiló). ${ }^{11}$

En su forma real, el mito de Abraham es una afirmación de la vida del ser humano contra la ley que aniquila (como la ley del mercado). Abraham, que se niega a sacrificar a Isaac, es la expresión genuina del sujeto viviente: encontrarse cara a cara el uno con el otro y mirar en la cara del otro la propia cara. El acto de Abraham relativiza la ley en relación con la posibilidad de vivir tanto de su hijo como de él mismo (Hinkelammert, 1995: 346-350).

Isaac es la víctima, cuya resistencia logra alterar la decisión de su padre, la convierte en decisión de vida. Abraham se hace libre al dejar libre a su hijo. La libertad la consiguen los dos en su encuentro, que es encuentro de seres humanos (sujetos vivientes). Dios ve en Abraham al padre de la fe. En este mito se descubre a la víctima y su derecho a no ser aniquilado. Aquí está la raíz de la fe. La fe consiste en reconocer que la ley no es válida ni verdadera si permite aniquilar. La posición de la fe es entonces la oposición al aniquilamiento, la fe es la afirmación de la vida, y no solo de la vida humana, sino también de Dios, pero del Dios de los seres humanos vivos y no del dios de los seres humanos muertos (Teología de la Liberación). La fe no es posible sin la afirmación del ser humano como ser humano. De la fe se derivan las conceptualizaciones que se hacen sobre la vida humana. La fe siempre está confrontándose con las razones que aprueban las leyes que conducen al ser humano hacia la muerte. En la interpretación ortodoxa cristiana, la fe consiste en cumplir la ley, incluso, si lleva al aniquilamiento (Hinkelammert, 2001: 45).

\section{El sacrificio de Ifigenia por su padre Agamenón ${ }^{12}$}

En la Ifigenia de Eurípides se halla la expresión de una libertad por sometimiento a la ley. Los hijos de la cultura griega se consideran libres por ley. Siempre está presente esta concepción de libertad. Se sienten libres de la esclavitud pero también se sienten libres para esclavizar. La libertad de Abraham es muy distinta, su liberación viene de negarse a aniquilar, no de una ley (Hinkelammert, 1998: 57-58). 
Eurípides (2000: 147-226) relata que Ifigenia, una de las hijas del Rey Agamenón y de la Reina Clitemnestra, debía ser sacrificada a la diosa Diana (Artemisa), para que los navíos griegos pudieran dejar la costa en dirección hacia Troya y combatieran. El viento era lento, estaba apagado, haciendo que las aguas estuvieran en calma y que las velas de las embarcaciones permanecieran planas, sin dar posibilidad de avanzar. Esta quietud fue provocada por la diosa Diana, debido a que Agamenón había matado a un animal en un bosque sagrado y alardeó ser mejor cazador que ella. Poco a poco la presión de los guerreros griegos aumentó, Agamenón tuvo que ceder. El adivino Calcas fue el encargado de sacrificar a Ifigenia: preparó el puñal y lo levantó para descargar el certero golpe, pero este instante se prolongó, se hizo largo y la Diosa no lo soportó. En lugar de Ifigenia hizo aparecer un animal para el sacrificio, y después la llevó a Taúrica, donde la convirtió en su sacerdotisa.

Agamenón expresó la libertad en el sacrificio de su hija. La destinó a ser sacrificada para asegurar el triunfo del ejército griego en la guerra de Troya. Esta libertad aparece directamente en su forma de aniquilamiento y en función del aniquilamiento. Todo en cumplimiento de la orden de la diosa Diana. Todo en cumplimiento de una ley (Hinkelammert, 1998: 57). Cuando Agamenón regresó de la hueste de Troya, Clitemnestra, su esposa, lo mató por mandar sacrificar a Ifigenia.

\section{La crucifixión de Jesús}

La crucifixión de Jesús viene de aplicar la ley. Así está escrito en el evangelio de Juan. Hay una ley y, según esta ley, tiene que morir. La aplicación de la ley es lo que crucifica. La causa de la crucifixión es la fe en la ley, el estar ciegos ante una ley que lleva hacia el aniquilamiento. No es Dios quien mata a su hijo, sino la ley (Hinkelammert, 2001: 46). Jesús es acusado por dos motivos. Pilato lo acusa de ser Rey de los Judíos. El sanedrín (tribunal) lo acusa de hacerse pasar por el hijo de Dios. Pilato acusa en nombre del imperio, el sanedrín en nombre de la ley. Ambas acusaciones provienen de la ley.

La acusación de Pilato además es hipócrita, dijo que no encontraba ningún delito en Jesús, pero lo anunció como Rey de los Judíos. Esta es una acusación directa, que en boca del máximo juez ya implicaba su condena a muerte. Presentarse con el título de Rey de los Judíos significaba soberbia, levantamiento contra Roma, que se castigaba con la crucifixión. Este título únicamente lo podía conceder el emperador. El sanedrín, acorralado por Pilato, lo acusa abiertamente y no encubre su denuncia. Lo acusa de hacerse pasar por hijo de Dios, lo que implicaba blasfemia (Hinkelammert, 1998: 29, 103). Jesús es crucificado por soberbia y blasfemia.

La crucifixión de Jesús no tiene sentido; sin embargo, él mismo tiene la certeza de que su muerte, por no tener sentido, salva. Salva al evidenciar que el aniquilamiento de seres humanos cumpliendo una ley es un sin sentido. El pecado del mundo, según Juan y Pablo de Tarso, está precisa- 
mente en aniquilar en nombre de la ley. La crucifixión de Jesús evidencia este pecado. Su muerte lo quita, pero no lo perdona, porque se comete creyendo que es por justicia. No hay conciencia de que se está pecando, debido a que no lo saben. Jesús, con su muerte, muestra que ahí está el pecado del mundo, y lo quita al hacerlo visible. Esta es la esperanza de vida que dio.

La forma que Jesús utilizó para evidenciar el pecado del mundo -sin embargo- puede ser paradójica: da esperanza de vida con su muerte. Da vida, muriendo. Para Hinkelammert (2010: 35) es una muerte testimonial, no un sacrificio. Ahora se trata de recuperar su vida no su muerte. La victoria jamás estará en la muerte por más que haya resurrección. También la resurrección es un llamado a recuperar la vida de Jesús, para que no vuelva a morir (Hinkelammert, 1998: 42-46). La ley no debe impedir la vida humana. Este es el mensaje de Jesús. Hinkelammert (Ibíd: 31-32) lo identifica con la ley del sábado. Para la ley, la violación del sábado era un pecado que se castigaba. Jesús trasgredió el sábado en términos de la ley y sostuvo que no había cometido pecado alguno, sino respetado la vida humana, que está por encima de la ley del sábado, porque las leyes son para la vida. Jesús no negó la ley del sábado; más bien, sostuvo que la santificación del sábado se pierde al no trasgredir la ley del sábado si niega la vida.

La ley debe estar sometida a un criterio de discernimiento, el cual no es decidido por el gobierno o por las empresas. La ley se puede trasgredir en cuanto afecte la vida. Jesús reclamó soberanía frente a la ley en nombre del ser humano: el ser humano no es para el sábado, sino el sábado es para el ser humano. Jesús extendió esto para todas las leyes. El ser humano no vive entonces para la ley del mercado, sino que la ley del mercado es para que el ser humano viva. No se trata de eliminar las leyes, sino de interpelarlas en nombre de la vida del ser humano.

\section{La idolatría: tema central entre Economía Ortodoxa y Teología de la Liberación}

La sociedad de hoy puede ser aniquilada en nombre del mercado. El mercado puede ser válido solo si respeta la vida humana, no es válido si su operación implica aniquilarla. El mercado -en tanto se vuelve total- adquiere vida propia y sustituye a la vida humana en el nivel de fundamento. El mercado total así ocupa la posición de fundante y abandona el lugar de fundado. La vida humana, en contraste, deja la posición de fundante y ocupa el lugar de fundada. El mercado total no es -por consiguiente- compatible con la vida humana y natural. La fe en la vida requiere de alternativas al mercado o ajustarlo a la vida, ambas opciones implican transformar la racionalidad económica vigente. El pecado del mundo se comete cumpliendo la ley que aniquila (ley del mercado), y no violándola (Pablo de Tarso). El mercado manejado por la Economía Ortodoxa, en su versión clásica y neoclásica, no es congruente con la vida humana y con la naturaleza; mucho menos, lo es el mercado total de la exposición neoliberal monetarista. No obstante, el mercado es necesario para el avance humano, pero no el 
mercado de la Economía Ortodoxa. El pecado del mundo se comente siguiendo la lógica de este mercado. La raíz del mal es el amor a la ley que aniquila (Pablo de Tarso). La raíz del mal es el amor al mercado. La misma Teología Ortodoxa presenta al mercado como un camino para llegar al cielo, maneja diversas parábolas para fomentarlo (la parábola de los talentos de Mateo). Los que no se arrojan al mercado con verdadero ahínco son considerados negligentes, individuos que no tienen gusto ni ánimo por la vida plena. La Teología Ortodoxa al pronunciar al mercado como justo es entonces una teología que acepta el aniquilamiento y que justifica la presencia de ídolos que exigen veneración.

La idolatría consiste en hacer dioses como producto de la imaginación dominadora del individuo. Se trata de dioses fabricados que luego se les adora como lo divino, como lo absoluto (total), como lo que origina todo lo demás (fundamento). Los dioses creados son ídolos sacralizados (Hinkelammert 1977a, Hinkelammert y Assmann 1989, Dussel 2006). Si el mercado del neoliberalismo monetarista tiene un lugar totalitario implica que fue sacralizado; siendo así, es un ídolo. Si el mercado total produce el aniquilamiento de todos, es entonces un ídolo que lleva a la muerte. El mercado total -por ende- es un dios de la muerte. No se trata de que el mercado por sí mismo sea un dios de la muerte, adquiere esta connotación cuando se manifiesta como punto de referencia para desprender todo lo demás: mercado total/juicio final. Para Marx (1982: I, 186-187) estaba claro: el mercado, el capital en cuanto se sacralizan se imponen al ser humano y lo dominan. Se convierten en ídolos. Basándose en el Salmo 115, 4-6, manifestó que el burgués hacía lo que le venía en gana. Tenía el lenguaje del sacrificador. Su dios era hecho por él mismo. Era un dios que tenía boca y no hablaba, tenía ojos y no veía, tenía orejas y no oía. Su dios era el mercado, su dios era el capital.

Goya sentenció: el sueño de la razón produce monstruos. Adaptado a la idolatría: el individuo, al diseñar sociedades perfectas, pero sobre todo al sentirse capaz de lograrlas (sueño de la razón), produce ídolos (monstruos). La idolatría del mercado tiene la cabeza de Janos: una de sus caras es el cálculo que hace el individuo vía mercado total (primera parte del sueño de la razón). La otra cara es la idea de que dicho cálculo lleva a la sociedad perfecta que promete el mercado total (segunda parte del sueño de la razón). En las dos partes del sueño de la razón (en ambas caras), el ídolo está presente (mercado total). No obstante, el cálculo de la sociedad perfecta -vía mercado total o por cualquier otra institución totalitaria- abstrae por completo al ser humano y a la naturaleza. El mercado total, en la búsqueda de su sociedad perfecta, aniquila al mismo individuo que la busca. De lograrse esta sociedad, sería una sociedad sin individuos. Hinkelammert identifica que la discusión entre Economía Ortodoxa y Teología de la Liberación está justamente en la idolatría. La idolatría no tiene sentido en la noción de sujeto viviente. Siguiendo con la sentencia de Goya y con la cabeza de Janos: una de sus caras es la acción del ser humano usando al mercado, al Estado u otras instituciones en tanto no se sacralicen (primera parte del sueño de la razón). La otra cara es la idea de que la 
sociedad obtenida preserva al ente que buscó esa sociedad: el ser humano (segunda parte del sueño de la razón). En las dos partes del sueño de la razón no hay ídolos presentes. Esta sociedad sería una sociedad con seres humanos. El mercado de la teoría económica clásica no es propiamente un mercado total, pero sí un medio que lleva a la muerte. El mercado de la Economía Ortodoxa, en cualquiera de sus vertientes, no comulga con el sujeto viviente, pero el sujeto viviente necesita del mercado. Se habla de otro mercado.

La existencia de aniquilados (excluidos, perdedores y ganadores) en la sociedad de hoy atestigua la existencia de un dios de la muerte, de una sociedad que carece de un Dios de la vida. La ausencia del Dios de la vida o la presencia del dios de la muerte es notable cuando la realidad pesa sobre los seres humanos. La ausencia es la presencia de lo ausente que se anhela (Tamez, 2001: 303-312). El Dios de la vida está presente cuando se alienta la existencia de una sociedad sin aniquilados.

\section{El ser humano: criterio de discernimiento de la Economía y Teología}

\section{Opción preferencial por el ser humano}

La Teología de la Liberación a finales de los sesenta tomó como identidad fundante de su praxis a los excluidos del mercado, los consideró como opción preferencial. Ante la pregunta de cómo y dónde actuaba Dios, esta corriente teológica respondía que en la liberación de los excluidos. Que la opción preferencial por los excluidos era la opción de Dios. Nunca habló de incluir a los excluidos en la lógica del mercado, incluirlos -así nada más- provocaría los mismos efectos: volverían a ser excluidos o tal vez perdedores o, en el mejor de los casos, ganadores. Cualquiera de las tres posiciones los arrojaría al lugar de los aniquilados. Parafraseando a Dussel: sería como echar vino nuevo en odres viejos. Para hablar de inclusión es necesario transformar la lógica del mercado de la Economía Ortodoxa.

Ahora ya no es solamente la opción por el excluido, sino es la opción por el ser humano, aunque la opción por el ser humano sigue siendo opción por el excluido, porque aquí, en este grupo, es donde comienza la amenaza contra la vida. La opción por el excluido no desaparece, es más clara a partir de la opción por la vida humana. La polaridad es entre mercado total y vida humana. Optar por el ser humano es una opción de vida y liberación (no es una opción de vida e inclusión), que viene del propio acto del ser humano y no de la ley (Hinkelammert, 1995: 357). Hacer una opción por la vida humana, desde la mirada del mercado total, parece algo irracional, porque es una opción preferencial. Optar en forma preferencial por aquellos que el mercado aniquila (excluidos, perdedores y ganadores) es cuestionar la propia racionalidad que tiene el mercado (Richard, 2004: 69-70). 
La opción preferencial por el ser humano es una opción desde el aniquilado. Aquí están los excluidos, perdedores y ganadores. Aquí están todos. Se trata de una sociedad donde quepan todos los mundos, sin exclusiones. Es como decía Rosa Khuno: todo para todos contando con todos. La expresión una sociedad donde quepan todos los mundos se diferencia de la expresión una sociedad donde quepan muchos mundos. Esta última expresión caracteriza los comunicados del movimiento zapatista en México, incluso, se manifiesta en las Declaraciones de la Selva Lacandona. El Subcomandante Marcos (1999: 78-80) la refuerza en su historia del ratoncito y el gatito: y entonces el ratoncito dijo ¡Ya basta! y agarró una ametralladora y acribilló al gatito. También en uno de los poemas con que se abre la Declaración de Principios del Ejercito Zapatista de Liberación Nacional (EZLN), Marcos escribe: es necesaria una cierta dosis de ternura para quitar de en medio a tanto hijo de puta que anda por ahí. Pero a veces no basta con una cierta dosis de ternura y es necesario agregar una cierta dosis de plomo. ${ }^{13}$

Optar solo por los ganadores es una opción destructiva y además es una opción auto-destructiva. La lógica del mercado comienza por los excluidos, pero no se detiene ahí. Sacrifica a todos. Los ganadores, los perdedores y los excluidos están expuestos a la destrucción, pero el excluido de manera más explícita, es el primer exponente de la amenaza. La posición del ganador es significativa en la figura de Abraham. Isaac es el perseguido y Abraham es el perseguidor. Abraham se convierte, decide no-aniquilar. Si Abraham no se hubiera convertido, Isaac hubiera muerto. La conversión implica entonces la transformación de los ganadores. En la liberación efectiva de la mujer, el mismo hombre (colocándolo como ganador) tiene que cambiar (convertirse), aunque en el cálculo de poder pierda. Cuando el esclavo se libera, tiene que cambiar el amo (ganador), aun cuando pierda poder. Cuando el obrero se libera, también el patrón (ganador) debe cambiar, aunque tenga menos en términos cuantitativos calculables (Hinkelammert, 2007: 411). La conversión del hombre, del amo y del patrón implica una vida mejor para ellos. Es su propia liberación (como la de Abraham). Se hablaría también de la conversión del gatito y del hijo de puta al que se refiere Marcos, no de su eliminación. En el mito del sacrificio de Ifigenia por su padre Agamenón, Hinkelammert (2010: 34-35) construye la posición que posiblemente hubiera liberado a Agamenón: interpretar la calma del viento que impedía llegar a Troya como una voluntad de la Diosa Diana para regresar pacíficamente a su casa y no hacer guerra. Ahora, en la sociedad actual, la liberación no es de grupos específicos, sino de toda la humanidad.

Si el ganador en el mercado se niega a convertirse, se acelera entonces el final de todos. Es la opción por la auto-destrucción. El pensamiento de Ciorán, el filósofo rumano, induce hacia esta opción (Hinkelammert, 1998: 251-252): como la catástrofe es la única solución, es justificado preguntarse si no es interés de la humanidad desaparecer ahora mismo, en vez de agotarse por la espera y perder la fuerza al exponerse a una agonía larga, en la cual podría perder toda ambición, incluso, aquella de desaparecer. 
Hinkelammert responde contra esta opción suicida: el individuo egoísta, poseedor y calculador no es el ser humano, sino lo que se ha hecho de él. No hay evidencias que muestren la eliminación del sujeto viviente. Al reducirse el ser humano a individuo, se invisibiliza su condición humana, pero no desaparece, no muere, sino es reprimida. Ciertamente, cuanto más el ser humano es reducido a ser individuo, menos posibilidad hay de dejar esta posición. El ser humano siempre tiene algo de él, aunque sea muy pequeño, fuera de la conducta que impone la ley del mercado. Si no fuera así, no se podría experimentar ni saber de que se vive en una sociedad autodestructiva (Hinkelammert, 2004: 15-16).

\section{Rebelión legítima: la afirmación del sujeto viviente}

Si el rostro del otro pide no me aniquiles, pide ser reconocido como sujeto viviente. De la respuesta no te aniquilaré del otro, ambos se constituyen como sujetos vivientes. Como sujetos se afirman en el no nos aniquilaremos. Esto subyace a la solidaridad que responde a este no nos aniquilaremos el uno al otro. Esto se dirige a la humanidad: todos juntos no nos aniquilaremos. Todos somos sujetos y llegamos a ser lo que somos al no aniquilarnos uno al otro (Hinkelammert, 1998: 257). La dialéctica del mercado de la Economía Ortodoxa es contraria: el ser humano debe convertirse en individuo egoísta, poseedor y calculador (competidor) que aniquile en la lucha (competencia) a los otros individuos (competidores). Esto es resultado de la construcción de la mano invisible de Adam Smith (teoría económica clásica) y del automatismo del mercado con tendencia hacia el equilibrio general (teoría económica neoclásica). El mercado se transforma en el ser supremo del ser humano y, por tanto, en un ídolo (neoliberalismo monetarista).

Lo que somos, y lo que llegamos a ser al auto-realizarnos, es ser sujetos vivientes. Este sujeto es el origen de la humanidad. En el inicio de la historia no hay un aniquilamiento, sino un no-aniquilamiento, un aniquilamiento que no se llevo a cabo. No aniquilar es el origen de la humanidad. La humanidad nace con Abraham, quien no sacrificó a su hijo Isaac. El amor al prójimo ya no se ve como yo amo al otro, el amor al prójimo se ve como ama al otro porque tú eres el otro. Esto es una dimensión distinta. El prójimo y tú forma una unidad. Amar al otro es amarse a uno mismo, noamar al otro es no-amarse a uno mismo. Entenderse como sujeto viviente es entenderse con relación al otro. El sujeto busca al otro como condición de su propia existencia. La relación con Jesús es siempre una relación con los otros seres humanos. Aquí está la fe. Jesús viene al interior del ser humano a partir de una relación social con otros seres humanos y no al revés, como si tuviéramos primero a Jesús, y luego lo lleváramos a los otros.

La figura de Jesús es paradigmática. Jesús es un transgresor de la ley, insiste en que no debe cumplirse si la misma vida determina que no hay que cumplirla. Toda vida social es una vida en el cual se establecen leyes, estableciendo a la vez el criterio de su transgresión: la vida misma. Los seres humanos son libres en la medida en la cual son capaces de relativizar 
la ley en función de su propia vida. Se habla de una soberanía del ser humano sobre la ley.

\section{Conclusiones}

Hinkelammert identifica un tema central en la discusión entre Economía Ortodoxa y Teología de la Liberación: la idolatría. En la idolatría se fabrican ídolos como producto de la imaginación dominadora del individuo, ídolos que luego se les adora. Se trata de ídolos que adquieren atributos de dioses. El mercado se ha transformado en un ídolo, en un dios que intenta solucionar todos los problemas del individuo, convertido -este último- en un simple objeto de su acción. Si el mercado produce el aniquilamiento de todos, es entonces un ídolo que lleva a la muerte; siendo así, es un dios de la muerte.

La discusión que genera Hinkelammert entre Economía Ortodoxa y Teología de la Liberación hace rechazar la hipótesis de que la moral y las ciencias orientadas al estudio de Dios sean terrenos que no tengan puntos de contacto con las disciplinas centradas en el análisis de las actividades económicas. El rechazo de esta hipótesis, sugiere que la Economía incorpore referencias teológicas y que la Teología -como disciplina social- se encarne en la realidad económica de la Tierra.

La Economía (Ortodoxa y Heterodoxa) y la Teología Convencional (también la Teología de la Liberación) están obligadas a incorporar en su campo de estudio nuevos esquemas que pongan en el centro de la reflexión al aniquilado del mercado: el ser humano. Optar preferentemente por este es buscar la vida, es garantizar la presencia de Dios. La Teología que opte por el ser humano es teología de liberación y de absolutización de la vida frente a cualquier ley. La gloria de Dios está precisamente en el ser humano (San Irineo). La vida del ser humano es el punto de partida para juzgar las perspectivas económicas. Las tasas de crecimiento económico son secundarias. La reflexión económica-teológica tiene que sostener que la vida humana está por encima de todo, que la vida es vivir en comunidad, sin aniquilados. Garantizar la vida asegura la permanencia del ser humano en la Tierra. La vida no significa vivir peligrosamente, como relata la filosofía de Nietzsche (1972): vivo toda mi vida con toda su fuerza explosiva en el grado en el cual excluyo (aniquilo) al otro, en cuanto experimento como vida la exclusión o la destrucción (aniquilamiento) del otro.

El aniquilamiento no está en el mercado sino en la manera en cómo se relaciona con el ser humano. El ser humano será libre en tanto logre transgredir al mercado de la Economía Ortodoxa. No será libre mientras se comporte atendiendo los principios de la ley del mercado. La libertad viene de relativizar esta ley en función de la vida. Esta es la libertad de Jesús. La fe consiste en reconocer que la ley no es válida si aprisiona, si conduce hacia el aniquilamiento. La posición de la fe es la oposición a la muerte. 


\section{Notas}

${ }^{1}$ Para efectos de este artículo, la palabra dios se escribe con D mayúscula cuando se refiere al Dios que está presente en las relaciones sociales de los seres humanos, se escribe con d minúscula cuando hace referencia a otros dioses.

${ }^{2}$ De ninguna manera se intenta reducir la obra de Hinkelammert en las líneas de este artículo, solo se busca sistematizar una pequeña parte de su amplia, profunda y compleja creación teórica.

${ }^{3}$ No considerar como exhaustiva esta composición de la Economía Ortodoxa, solo se presenta una referencia general.

${ }^{4}$ En este trabajo no se hace investigación bíblica.

${ }^{5}$ La interpretación a la obra de Hinkelammert es responsabilidad exclusiva de los articulistas.

${ }^{6}$ Esta lógica sería tomada más tarde por la doctrina económica neoclásica bajo la noción de equilibrio general (Walras). El equilibrio general de los mercados se deriva de la interdependencia de las mercancías por el grado de complementariedad y sustitución que tienen: el desplazamiento en el punto de equilibrio de mercado de una mercancía provocará desplazamientos en los mercados de otras mercancías, estos últimos en las de otras y así sucesivamente. Las variaciones provocarán efectos retroactivos, correctores o re-alimentadores sobre el mercado original (mercado donde se suscitaron los primeros desplazamientos). Si no existe intromisión externa (ceteris paribus) este proceso conducirá al equilibrio general.

${ }^{7}$ Este comentario parece irónico, pero la expansión de las mercancías vía mercado por toda la Tierra ha tocado fin. El crecimiento de la economía de mercado necesita áreas externas (Wallerstein) o reducir al máximo la vida útil de las mercancías.

${ }^{8}$ Por Teología Ortodoxa entiéndase teología institucionalizada cerrada en conjuntos dogmáticos eternos y absolutos (Teología Convencional).

${ }^{9}$ Borges (S/f), en el poema El Tango, introduce en una atmósfera similar de aniquilamiento. Habla de un grupo de hombres malévolos y matones formadores de una secta del cuchillo en los callejones polvorientos de tierra de los suburbios bonaerenses, que sin amor u odio, simplemente se acuchillaron. Era la sociedad del acuchillamiento: Ñato, en un puente de la vía, acuchilló a su hermano, ambos eran matones. Con esta muerte, Ñato quedaba igual que su hermano en cantidad de acuchillamientos.

${ }^{10}$ Esta parte de El Capital es clave en el análisis crítico de la Economía Ortodoxa que hace Hinkelammert, explica que ahí está el quiebre del capitalismo (Hinkelammert, 2007: 408).

${ }^{11}$ Para profundizar sobre este mito véase Hinkelammert (1989).

${ }^{12}$ Este mito no solo tiene una versión, tiene varias, se diferencian por las posiciones dadas a los personajes principales: Agamenón, Clitemnestra e Ifigenia. Esquilo, Eurípides y Goethe son quienes juegan con los personajes. El tratamiento que hace Eurípides lleva más lejos que los otros dos tratamientos.

${ }^{13}$ Con este comentario no se intenta reducir las aportaciones teóricas ni la dinámica social/ política/militar del EZLN. 


\section{Bibliografía}

Borges, Jorge Luis (S/f), El tango, en http://www.palabravirtual.com/ index.php?ir=ver_voz.php\&wid=2401\&p=Jorge\%20Luis\%20Borges\&t= El\%20tango\&o=Jorge\%20Luis\%20Borges

Dussel, Enrique (2006), 20 Tesis de Política, Siglo XXI editores y Centro de Cooperación Regional para la Educación de los Adultos en América Latina y el Caribe, México.

Eurípides, (2000) Tragedias Eurípides, Editores Mexicanos Unidos, S.A., México.

Hinkelammert, Franz (2012), Razón instrumental y espacio mítico (causalidad y contingencia): la modernidad y sus mitos, en http://www.pensamientocritico.info/component/content/article/58-goticasde-economia-critica/290-razon-instrumental-y-espacio-mitico-causalidady-contingencia-la-modernidad-y-sus-mitos.html

Ídem (2010), La maldición que pesa sobre la ley. Las raíces del pensamiento crítico en Pablo de Tarso, Editorial Arlekín, San José de Costa Rica.

Ídem (2007), Pensamiento crítico y crítica de la razón mítica, en Theologica Xaveriana, Vol. 57, No. 163, Facultad de Teología, Pontificia Universidad Xaveriana, Bogotá.

Ídem (2004), La vida es más que el capital. La democracia de ciudadanos y el proyecto de la sociedad en la que quepan todos los seres humano, en Pasos, DEI, San José de Costa Rica.

Ídem (2003), El asalto al poder mundial y la violación sagrada del imperio, DEI, San José de Costa Rica.

Ídem (2001), Teología en el acontecer de una vida. Entrevista de Germán Gutiérrez, en Itinerarios de la razón crítica: homenaje a Franz Hinkelammert en sus 70 años, José Duque y Germán Gutiérrez (editores), DEI, San José de Costa Rica.

Ídem (1998), El grito del sujeto. Del teatro-mundo del evangelio de Juan al perro-mundo de la globalización, DEI, San José de Costa Rica.

Ídem (1995), Cultura de la esperanza y sociedad sin exclusión, DEI, San José de Costa Rica..

Ídem (1989), La fe de Abraham y el Edipo occidental, DEI, San José de Costa Rica..

Ídem y Hugo Assmann (1989), A idolatría do mercado. Ensaio sobre economía e teología,Vozes, Sao Paulo. 
Ídem (1977), Ideologías del sometimiento, EDUCA, DEI, San José de Costa Rica.

Ídem (1977a), Las armas ideológicas de la muerte, EDUCA, DEI, San José de Costa Rica.

Marx, Karl (1966), El Capital, Tomo I, Fondo de Cultura Económica (FCE), México.

Ídem (1982), Obras fundamentales, FCE, México.

Marcos, Subcomandante (1999), La historia del ratoncito y el gatito en Don Durito de la Lacandona, Centro de Información y Análisis de Chiapas, A.C., San Cristóbal de Las Casas.

Nietzsche, Friedrich (1972), Más allá del bien y del mal, Alianza, Madrid.

Tamayo, Juan (2001), Hacia una teología liberadora desde la exclusión, en Itinerarios de la razón crítica: homenaje a Franz Hinkelammert en sus 70 años, José Duque y Germán Gutiérrez (editores), DEI, San José de Costa Rica..

Tamez, Elsa (2001), Leyendo la Biblia bajo un cielo sin estrellas, en Itinerarios de la razón crítica: homenaje a Franz Hinkelammert en sus 70 años, José Duque y Germán Gutiérrez (editores), DEI, San José de Costa Rica..

Recibido: 07.10.2012

Aceptado: 10.04.2013 